\title{
An Overview on Decision Making Under Risk and Uncertainty
}

\author{
Manjushree Kurhade ${ }^{1}$, Rahul Wankhade ${ }^{2}$ \\ ${ }^{1}$ M.E. Construction Engineering \& Management, PRMCEAM Badnera, Maharashtra, India \\ ${ }^{2}$ Prof. Civil Engineering Department, PRMCEAM Badnera, Maharashtra, India
}

\begin{abstract}
Decision is nothing but a conclusion reached after consideration or it is the tendency of people to become certain about anything which they wants to do. Whereas decision making is a process of selecting the best among the different alternatives. Decisionmaking involves the selection of a course of action from among two or more possible alternatives in order to arrive at a solution for a given problem. Risk and uncertainty is incorporated during the decision making. Risk is nothing but the situation involving exposure to danger. Also the uncertainty is the lack of certainty, a state of having limited or incorrect knowledge where it is impossible to exactly describe the existing state, a future outcome. The sources of risk and uncertainty in decision making are discussed, emphasizing the distinction between uncertainty and risk. This paper introduces concepts, principles and approaches for addressing rick \& uncertainty in decision making \& provides a brief overview of risk mapping also the decision tree.
\end{abstract}

Keywords: Decision making, Risk, Uncertainty, Decision tree.

\section{Introduction}

\subsection{General}

In our day to day life we take lot of decisions, like purchasing any object or to do investment for that object. In these decisions some are simple in the manner but when there are many possibilities to take the decision at that time risk and uncertainty occurs that which possible condition I should take for the better output. Today by experience we know that few people make decisions after the welldeliberated calculations, no matter if the decision situation is in a job situation or in a personal life. We also know that during decision making under risky situation, people often neglect the normative rules and that they often make decisions by intuition or on "a hunch" that seems correct. The descriptive theory gives us some explanations that why people make decisions the way they actually do by neglecting suggested normative rules for decision-making under risk and uncertainty and for simplicity and instance people often use well-known paths for decision making. In any organization, its structure as well as the culture of organizations must be examined as they both influence the decision-making processes to a great extent ${ }^{[5]}$.

Risks and uncertainties of project developments arises from various sources of errors including data, model errors and forecasting errors. It was found that the most powerful factors affecting risk and uncertainty were resulted from forecasting errors. Also data errors and model errors were found to have trivial or insignificant effects. It was argued by many analysts that scenarios do not forecast what will happen but scenarios indicate only what can happen from given alternatives ${ }^{[1]}$.

Generally it is assumed that economic decisions were made when there is a complete condition of certainty and decision of both consumers and producers depend upon the accurate knowledge of firm, consumer and market condition.
Sometimes economic decisions are made by use of improper information and the outcome of these decisions cannot, therefore be known with any degree of accuracy. Sometimes a manager cannot know, for example, whether the introduction of a new product will be profitable because of the uncertainty of macroeconomic conditions, consumer tastes, and reactions by competitors, resource availability, input prices, labour unrest, political instability, and so forth. Uncertainty associated with decisions made at any point in time and the uncertainty of outcomes associated with those decisions are simultaneously tends to increase further we project into the future.

\subsection{Risk-Informed Decision Making}

A lot of opportunities or variety of methods might be there to try and overcome the challenges that uncertainty poses for decision makers. On one end of the spectrum are probabilistic risk and decision analysis methods. On the other end of the spectrum are ad-hoc methods (those developed specifically for a particular decision) and even intuition, if that can be called method. In Contrast to probabilistic risk and decision analysis, ad-hoc methods and intuition are unlikely to provide a defensible basis for decision making. This is particularly true in cases where decision makers hold the public trust, which is the case when potential losses would be distributed across a population that may have had little or no input into a decision process. In such cases, the use of a rational and rigorous approach to decision making is needed both to protect the decision maker and to protect the public. Decision having Probabilistic risk and the decision analysis is the most (and some would say "the only") rigorous engineering approach to difficult decision-making problems involving uncertainty.

Throughout the process of decision making, it is important to know that the decision modelling activity is not about "getting the answer." Rather, it is finally about learning more about the decision problem itself. A good decision 


\section{International Journal of Science and Research (IJSR) \\ ISSN (Online): 2319-7064}

Index Copernicus Value (2013): 6.14 | Impact Factor (2015): 6.391

model will lead the decision maker to a more sophisticated understanding of his particular decision problem by enabling him to pick the problem up and explore it or inspect it from a variety of different angles.

\subsection{Organizing the Analysis}

For calculating the risk and decision analysis and to support decision making, four steps can be considered:

1) Made the framing for decision problem.

2) Modelling the decision.

3) Analysing and interpreting the results.

4) Communicating the results to decision makers ${ }^{[3]}$.

The first, three steps are important in organising the decision making. However, communicating the results to decision makers is equally important. A thorough and well executed analysis at is poorly communicated will not provide decision makers with the understanding they need to address uncertainty with confidence. Investments done in analysing a decision problem should reflect the importance of potential losses associated with choosing a sub-optimal alternative. Higher opportunity costs justify greater investments in decision analysis. In addition with deciding how much to invest in analysing the problem, the timing of that investment is also critical. Further in this study we will discuss about most frequently used criteria for choosing best decision among alternative decisions, how probabilities are used in the decision-making process, how decisions affect when made at an early stage than decision made at a later stage, and how attitudes toward risk can affect the analysis.

\section{Theoretical Aspect}

\subsection{Concept of risk and uncertainty}

\section{a) Risk}

In the simple manner risk is the probability of deciding the method or the opportunities for the better output. The objective of risk assessment is to conduct an assessment to bode negative effects so that adverse outcome can be minimized. In many literature the word "risk" defines as comprising of following two elements:

1)The probability (or likelihood) of occurrence of a negative event during the lifetime of operation of a facility

2)The resultant consequence when a negative event has taken place.

The first term involves risk assessment, whilst the second term is risk management. Risk assessment is a scientific task and risk management is the subject of finding out regulatory measures based on risk assessment and considerations of a legal, political, social, economic, environmental and engineering nature risk issues ${ }^{[1]}$.

A situation where the outcome is unknown to the decisionmaker, that means decision-maker is not sure which outcome will occur, is called as a risky situation.

b) Uncertainty
Uncertainty is state of lack of knowledge. The various fields which is concerned with uncertainty have no common agreement on the definition, terminology, or classification of uncertainty. Also we can say that the Uncertainty - uncertain events that we do not even know how to describe. The word "uncertainty" emphasizes that choice of decision-making must be made on the basis of incomplete knowledge about projects that do not yet physically exist. Uncertainties arise from three sources of errors, namely

1)Data errors (uncertainties about past events)

2)Forecasting errors (uncertainties about future events)

3) Model errors (residual errors, different between Observed and model values)

\section{Data Errors}

The errors related with the technical problems are known as the data error. Data errors stem from measurement errors, sampling errors and simple human errors. Uncertainties due to data error can be measured by using statistical techniques. Data errors can be reduced by collecting more past data.

\section{Forecasting Errors}

Forecasting error is related with the uncertainty about "future events". As we know economic evaluation of the future is questionable. There is a limit to our ability to reduce forecasting errors. No matter how hard we tried and used advanced techniques the reason is the future is unknowable [1]

\section{Model Errors}

Model errors represents the residual error which is output of difference between observed and model values. Model error may occurs due to the impossibility towards perfectly representing the real world in a mathematical model. Quantifications of economic benefits involves the use of forecast traffic speeds and delays, fuel prices, national income and time valuation, and etc. contain model errors ${ }^{[1]}$.

\subsection{Assessment of Risk and Uncertainty}

It was found that many European countries use scenarios for the investigation of the effect risk and uncertainty of project investments which include scenario investigation, sensitivity assessment and probability-based assessment. Current practices for the assessment of risk and uncertainty states on scenario analyses.

The methodologies are briefly discussed below.

\subsubsection{Scenario Analyses}

Scenarios analyses is related with investigating the different alternatives for the option which can performs well with minimum risk. Currently, scenario assessment is a basic tool used to assess risk and uncertainty about future. Since the future is uncertain with involvement of risk one way we can deal with this uncertainty and assess risk is to constructing possible scenarios and looking for the options which performed well with minimum risk. Scenario analysis can begin with defining alternative scenarios, its criteria, impacts and risks. Assessment impacts and risks may involve creating scorecard for each scenario. Decision-making may 


\section{International Journal of Science and Research (IJSR) \\ ISSN (Online): 2319-7064}

Index Copernicus Value (2013): 6.14 | Impact Factor (2015): 6.391

be done based on the scenarios that possess the most benefit cost effective, minimum risks and impacts. Scenario assessments do not forecast what will happen or probability of occurrence they indicate what can happen from different given alternatives ${ }^{[1]}$.

\subsubsection{Sensitivity Analyses}

Sensitivity analyses are nothing but the identification of main sources of uncertainty. It is conducted to identify whether there are some variables which contribute greater uncertainty to the forecasted other. Input variables which have high susceptibility for future forecasts may need to be measured first with more analyses and the uncertainties of highly susceptible factors may be considered in decisionmaking. The main objective of sensitivity analysis is to identifying main effects and interaction effects of input variables. The uncertainties arises due to data errors and forecasting errors were considered in the sensitivity analysis [1].

\subsubsection{Probability-based Assessment}

Probability-based assessment is nothing but the identification of various uncertainties and it is purely statistical method. As probability-based assessment is the statistical method then mathematical functions of related decision-making factors established first then uncertainties of input variables of that functions are quantified and modeled by probability distribution and its statistical parameters (i.e. mean and coefficient of variation). The outcome from the analysis is the probability distributions of output parameters.

Figure 2.1 shows schematic chart of probability-based assessment. The probability-based assessment can also apply to different scenarios

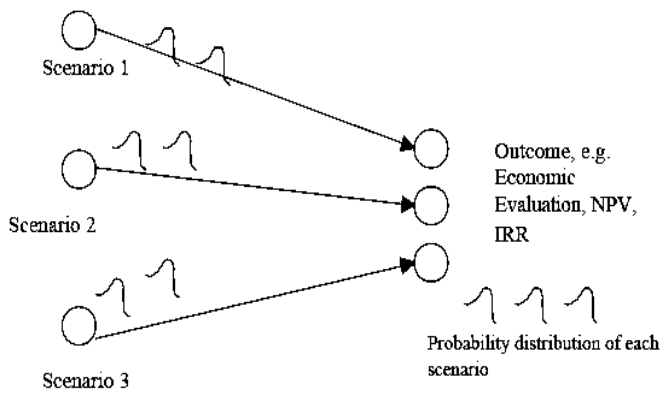

Figure 2.1: schematic chart of probability-based assessment

The process began with the identification of probability distribution of each input variable, including data errors, forecasting errors and model errors. The probability distributions were developed based on assumption and derived from samplings ${ }^{[1]}$.

\subsection{Distinction between Risk and Uncertainty}

As we know that risk is the situation where outcome is unknown to decision maker or that may or may not be realized in the future. An adverse effect is a loss of some sort. A decision maker faces a risk if the outcome of a decision is uncertain and may be adverse. Risk can be fully defined by a set of three things, including: 1) a set of mutually exclusive and collectively exhaustive scenario conditions under which the possible outcomes may be realized, 2) a set of outcomes for each possible scenario, and 3) a probability of occurrence for each possible scenario. Using this definition, risk can be described using a lossexceedance curve in which scenario outcomes involving potential losses are plotted on the $x$ axis and the probability of exceeding those losses is plotted on the $y$ axis. The lossexceedance curve is sometimes called a risk curve.

Figure 2.2 illustrates three risk curves, which could represent the potential losses associated with three decision alternatives (A, B, and $\mathrm{C}$ ). The $y$ intercept gives the probability that the costs associated with choosing an alternative will exceed the benefits of that alternative. In Figure 2.2, Alternative $C$ entails the largest potential losses.

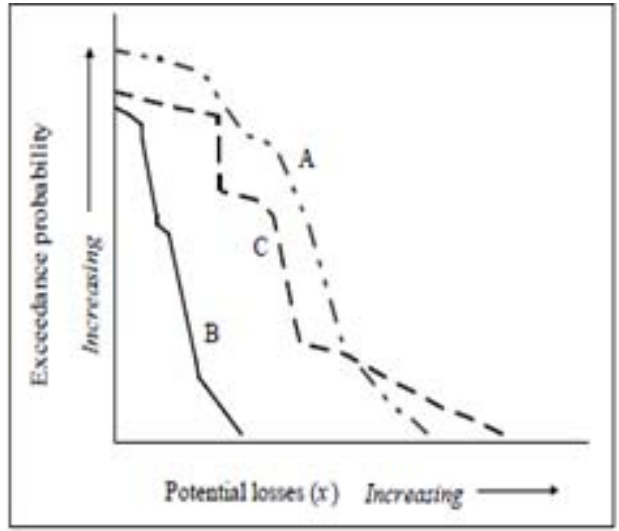

Figure 2.2: Three risk curves

Alternatives A and $\mathrm{C}$ are riskier than Alternative B because these alternatives lead to larger losses with higher probabilities. It is important to note that these risk curves by themselves do not provide sufficient information to decisionmaker to choose among the three alternatives. A decision maker also needs information on the potential benefits of each alternative and their probabilities. An understanding of the decision maker's attitudes toward accepting risks is also important need ${ }^{[3]}$.

\subsection{Identification of Various Risks for Decision Making}

Risks have always been a part of life. For getting the possible outcome with minimum risk identification of risk is necessary. Here some types of risks are given which is mostly related to infrastructure asset. When investments are done for infrastructure asset investment, political, social and environmental and other related risk issues may not be avoided in decision-making. Risk levels were based on five different risk scales namely rare, unlikely, moderate, likely and almost certain and its consequences are classified into five categories namely insignificant, minor, moderate, major and catastrophic. The identification and classification of the risk related issues are as follows. Details of these risks are given in Table 2.1. 


\section{International Journal of Science and Research (IJSR) \\ ISSN (Online): 2319-7064}

Index Copernicus Value (2013): 6.14 | Impact Factor (2015): 6.391

Table 2.1: classification of risks and consequences (Australian Defense Organization2002)

\begin{tabular}{|c|c|c|c|c|c|}
\hline $\begin{array}{c}\text { Risk } \\
\text { Category }\end{array}$ & Causes & Consequences & $\begin{array}{c}\text { Consequence } \\
\text { Rating }\end{array}$ & $\begin{array}{l}\text { Likelihood } \\
\text { Rating }\end{array}$ & $\begin{array}{c}\text { Risk } \\
\text { Rating }\end{array}$ \\
\hline $\begin{array}{l}\text { Political } \\
\text { Risk }\end{array}$ & $\begin{array}{l}\text { Government } \\
\text { policy changes, } \\
\text { i.e. Taxation, } \\
\text { privatisation } \\
\text { and competition }\end{array}$ & $\begin{array}{l}\text { Reduced } \\
\text { spending on } \\
\text { maintenance } \\
\text { and trend } \\
\text { toward } \\
\text { development of } \\
\text { only } \\
\text { commercially } \\
\text { viable } \\
\text { infrastructure } \\
\text { projects }\end{array}$ & Major & Unlikely & Significant \\
\hline $\begin{array}{l}\text { Economic } \\
\text { Risk }\end{array}$ & $\begin{array}{l}\text { Reduced } \\
\text { access to } \\
\text { government } \\
\text { funds, providing } \\
\text { transport } \\
\text { infrastructure in } \\
\text { key locations, } \\
\text { rationalization } \\
\text { of industry } \\
\text { players as } \\
\text { escalating fixed } \\
\text { costs lead to } \\
\text { smaller margins } \\
\text { and intense } \\
\text { competition }\end{array}$ & $\begin{array}{l}\text { Reduction in } \\
\text { maintenance / } \\
\text { development of } \\
\text { infrastructure, } \\
\text { increased usage } \\
\text { charges, } \\
\text { reduced } \\
\text { efficiency of } \\
\text { infrastructure } \\
\text { and greater of } \\
\text { total funds } \\
\text { invested on } \\
\text { maintenance } \\
\text { rather than new } \\
\text { development }\end{array}$ & Major & Unlikely & Significant \\
\hline $\begin{array}{c}\text { Social// } \\
\text { Environmental } \\
\text { / Cultural } \\
\text { Risk }\end{array}$ & $\begin{array}{l}\text { Increased } \\
\text { demands by } \\
\text { society to } \\
\text { reduce } \\
\text { environmental } \\
\text { damage, } \\
\text { increase public } \\
\text { awareness of } \\
\text { life, civil rights } \\
\text { issues, } \\
\text { expectation of } \\
\text { fast service }\end{array}$ & $\begin{array}{l}\text { Greater costs for } \\
\text { infrastructure } \\
\text { projects may be } \\
\text { incurred in order } \\
\text { to satisfy } \\
\text { environmental, } \\
\text { social criteria } \\
\text { and constraints }\end{array}$ & Minor & $\begin{array}{l}\text { Almost } \\
\text { Certain }\end{array}$ & Significant \\
\hline $\begin{array}{c}\text { Technology } \\
\text { Risk }\end{array}$ & $\begin{array}{l}\text { Increasing } \\
\text { reliance on the } \\
\text { use to IT and } \\
\text { communications } \\
\text { to design, } \\
\text { operate and } \\
\text { manage } \\
\text { transport } \\
\text { infrastructure } \\
\text { and collect } \\
\text { revenue }\end{array}$ & $\begin{array}{l}\text { Interdependency } \\
\text { results in greater } \\
\text { vulnerability to } \\
\text { any IT } \\
\text { interruption of } \\
\text { services }\end{array}$ & Major & $\begin{array}{l}\text { Almost } \\
\text { Certain }\end{array}$ & High \\
\hline
\end{tabular}

\subsection{Risk Assessment Frame Work for Decision Making} Process

After the identification of risk, proper assessment and management of risk is necessary and for that a necessary frame work is should be there. This framework includes both quantitative and qualitative risks in the assessment and is shown in Figure 2.3

Risk analysis is the quantitative technical assessment and can be estimated by the probability (P) of an event of occurrence over a specified period of time and its related consequences. Risk is a function of the probability of occurrence and the magnitude of consequences $(\mathrm{M}), \mathrm{R}=\mathrm{f}(\mathrm{P}, \mathrm{M})^{[1]}$.

Public Risk Perception is the measure of public reactions to risk and. Public risk perception can be quantified qualitatively and quantitatively. Perception is a judgment of the degree to which some one likes or dislikes some objects, concepts, projects or persons it means risk perception describes people's feelings about risk. Objective and Subjective data is the behavior data that reflect agreement or opposition to a project introduced.

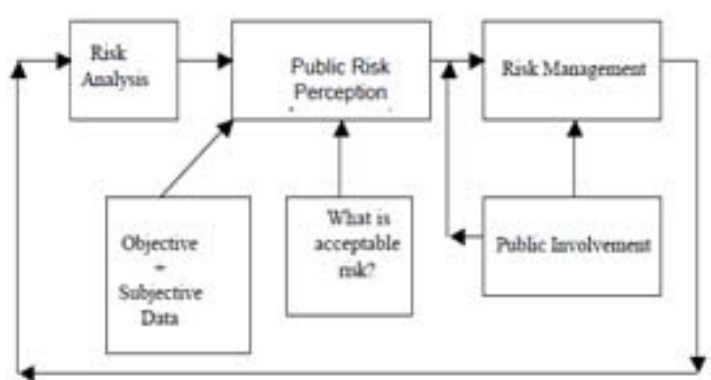

Figure 2.3: Framework for risk assessment

Acceptable risk is the degree of risk to be accepted and in many instances, the public decided which levels of potential risks are acceptable.

Risk Management is the final process to be implemented in the process of risk assessment to ensure that risks are kept at minimum and do not have adverse effects to the public. It is a part of a decision-making process that entails consideration of political, social, economic, engineering information and cost-benefit with risk related information to develop analyses and compare and make a decision on appropriate solutions.

Figure 2.4 describes step-by-step implementation of risk assessment. Details of each step are given below:

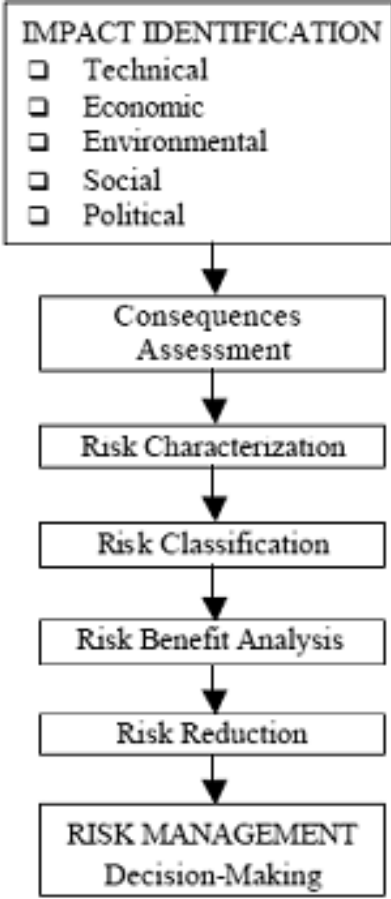

Figure 2.4: Step by step risk assessments

Impact Identification as the name indicate is the identification of adverse effects on economic, environment, social, political and technology resulting from a project development.

Consequences Assessment is the assessment of impacts and exposure chance of the incidence, severity and adverse effects resulting from a decision-making on the public.

Risk Characterization is the approximation or estimation of the event and severity likely to occur in a human population or environmental components due to actual or predicted 


\section{International Journal of Science and Research (IJSR) \\ ISSN (Online): 2319-7064}

Index Copernicus Value (2013): 6.14 | Impact Factor (2015): 6.391

exposure to the adverse effects resulting from a decisionmaking.

Risk Classification is the distribution or the evaluation of risks in order to decide if risk reduction is required.

Risk Benefit Analysis is the assessment whether taking into account certain risks gains benefits. It is a task that decisionmakers have to consider not only the risk assessment but also other aspects such as technical feasibility, costs-benefits, social and cultural, political factors as well as uncertainties. Risk Reduction is the process which reduces risk and protect man and/or environment from the risks identified ${ }^{[1]}$.

\subsection{Risk Mapping For Decision-Making}

Once the risks have been assessed a major difficulty still remains, synthesizing the distinct impacts of risks. Risk mapping can be included in the multi-criteria decisionmaking framework to present the results in such a way that it facilitate the comparison and accounting for risks in the final decision-making process. Risk mapping technique has been used by a major Chemical engineering company to identify key strategic environmental, health and safety issues. Risk mapping is a tool to manage risk and adjust project allocations based on cost-benefit and risk.

In figure $\mathrm{X}$-axis shows the magnitude of the resultant consequences, which may range from being insignificant to highly significant. Intolerable region is the region which shows high risk and significant impact of the consequences is significant. Risks and its resultant consequences that fall within intolerable region need to be immediately addressed and resolved. Tolerable region is the region where risks are low and the impact of the resultant consequences is low. An event that falls within tolerable region may be considered to be insignificant and may be ignored at the stage of decisionmaking. Moderate region shows region where risks and the impact of the consequences are at moderate levels. Events falling within this region need to be taken into account before a final decision can be made ${ }^{[1]}$.

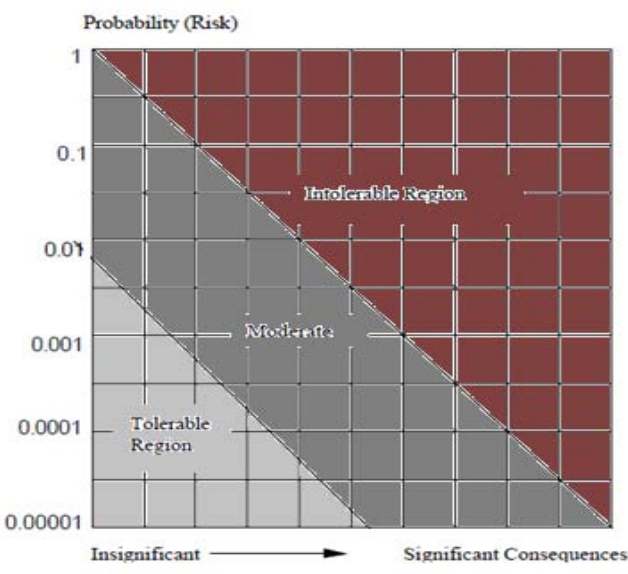

Figure 2.5: Risk map

\subsection{One Stage Decision-Making}

As the name indicated, decision-making in case of single stage decision problems calls for, 1 . Identification of the courses of action available to the decision maker in the face of various possible events, 2. Developing a pay-off matrix, and 3. Choosing a particular course of action in accordance with some principal.

For one or single stage decision making problems pay-off and regret tables are developed. A pay-off is a conditional value or a conditional profit, loss, or may be, a conditional cost. It is called as conditional because it associated with each course of action is a certain profit/loss, given that certain event has occurred. A pay-off table represents the matrix of the conditional values associated with all the possible combinations of the acts and the events. The resultant outcomes of the various combinations of the acts and events (the state of nature) can alternatively be expressed in terms of opportunity loss. It is called as regret, the opportunity loss is defined as the amount of pay-off foregone by not adopting the optimal course of action - that which would give the highest pay-off, for each possible event. The pay-off matrix can be transformed into opportunity loss by subtracting from the highest profit value in each row, all the other value in that row.

After setting up the pay-off table (or the opportunity loss table) we proceed to take the decision. Under several rules, or criteria, decision may be taken. The selection of an appropriate criterion depends on factors like the nature of decision situation, attitude of the decision-maker, and so on.

\subsubsection{Decision Rules for Decision under Risk}

The decision situations wherein the decision-maker chooses to consider a several possible outcomes and the probabilities of their occurrence can be stated are called decision under risk. The possibilities of various outcomes may be determined objectively from the past records. Under condition of risk there are generally two criteria to choose from.

\section{a) Maximum Likelihood Principle}

Under this principle, the decision-maker first considers the event that is most likely to occur. He then decides for the course of action which has the maximum conditional payoff, corresponding to this event (of course, when the pay-off matrix is in terms of costs, then the action with the least conditional pay-off would be chosen.)

\section{b) Expectation Principle}

In this principle, the decision-making is done on the basis of the expectation principle when there is a risky situation. With the event probabilities assigned, objectively or subjectively as the case may be, the expected pay-off for each strategy is calculated by multiplying the pay-off values with their respective probabilities and then adding up these products.

\subsubsection{Decision Rules for Decision under Uncertainty}

A situations where there is no way in which the decisionmaker can assess the probabilities of the various states of nature are called decision under uncertainty. The several principles which may be employed for taking decision in such condition are as follows. 


\section{International Journal of Science and Research (IJSR) \\ ISSN (Online): 2319-7064}

Index Copernicus Value (2013): 6.14 | Impact Factor (2015): 6.391

\section{a) Laplace principal}

The Laplace principle is based on the simple philosophy that if we are uncertain about the various events then we may treat them as equally probable. Under this assumption, the expected (mean) value of pay-off for each strategy is determined and the strategy with highest mean value is adopted. Of course, if the pay-off are in terms of costs, we choose the strategy with the lowest average cost.

\section{b) Maximin or Minimax Principle}

This principle is adopted by pessimistic decision-maker who are conservative in their approach. Using this principle, the minimum pay-offs resulting from adoption of various strategies are considered and among these values the maximum one is selected. It involves, therefore, choosing the maximum profit from the set of worst or the minimum profits.

\section{c) Maximax or Minimin Principle}

The maximax principle is optimist's principle of choice. This principle suggests that for each strategy, the maximum profit should be considered and the strategy with which the highest of these values is associated should be chosen. The optimist obviously desires a chance for the maximum pay-off in the decision matrix.

\section{d) Hurwicz Principle}

The Hurwicz principle of decision-making stipulates that a decision-maker's view may fall somewhere between the extreme pessimism of the maximin principle and the extreme optimism of the maximax principle. This principle provides a mechanism by which different levels of optimism and pessimism may be shown. For this, an index of optimism, $\alpha$, is defined on scale ranging from 0 to 1 . An $\alpha=0$ indicates extreme pessimism while $\alpha=1$ represents extreme optimism.

\section{e) Savage Principle}

The savage principle is based on the concept of regret and calls for selecting the course of action that minimizes the maximum regret. It is alternatively known as the principle of minimax regret. The regret matrix is derived from the payoff matrix then the maximum regret value corresponding of each of the strategies is determined and the strategy which minimizes the maximum regret is chosen ${ }^{[9]}$.

\subsection{Multi-Stage Decision Making}

In analyzing multiple stage decision situations, we have to evaluate the decision proceeding in a backward manner by evaluating the best course of action at the later stage to decide the best action at the earlier stages. For this purpose, the decision tree or the decision flow diagram is a very effective device.

\subsubsection{Decision Tree}

A decision is a choice between two or more courses of action. Decision making under uncertainty is the process of choosing between different courses of action when the outcomes of those actions are uncertain. A decision tree is like a decision support tool that uses a tree like graph or model of decision and their possible consequences, including chance event outcomes, resource costs, and utility and it is one way of showing an algorithm. The most basic technique in decision theory is the decision tree. Here as an example, the question of whether to regulate air pollution to improve forest health. Suppose you are asked to provide an opinion on whether or not air pollution should be regulated to improve forest health. Three responses are possible:

1)Pollution is affecting forest health and should be regulated

2)Pollution is not affecting forest health and should not be regulated.

3) The evidence is inconclusive (so I need some grant money to study the problem, and I'll get back to you).

Of course, inattentive of your opinion about whether pollution is affecting forest health, pollution either is having an effect or it is not having an effect and their decision is informed by the advice we give them, but their decision on whether to regulate or not depends on whether they think that pollution is affecting forest health, and just as our opinion can be wrong, their decision can be wrong too.6Notice that there are 12 possible outcomes: 3 answers we might give to the question, 2 possible states of the world, and 2 possible decisions by the regulator. These possibilities and their consequences can be summarized in a decision tree.

Figure 2.6 Decision Tree For Analysis Of Regulation On Air Quality Intended to Improve Forest-Health. 


\section{International Journal of Science and Research (IJSR) \\ ISSN (Online): 2319-7064}

Index Copernicus Value (2013): 6.14 | Impact Factor (2015): 6.391

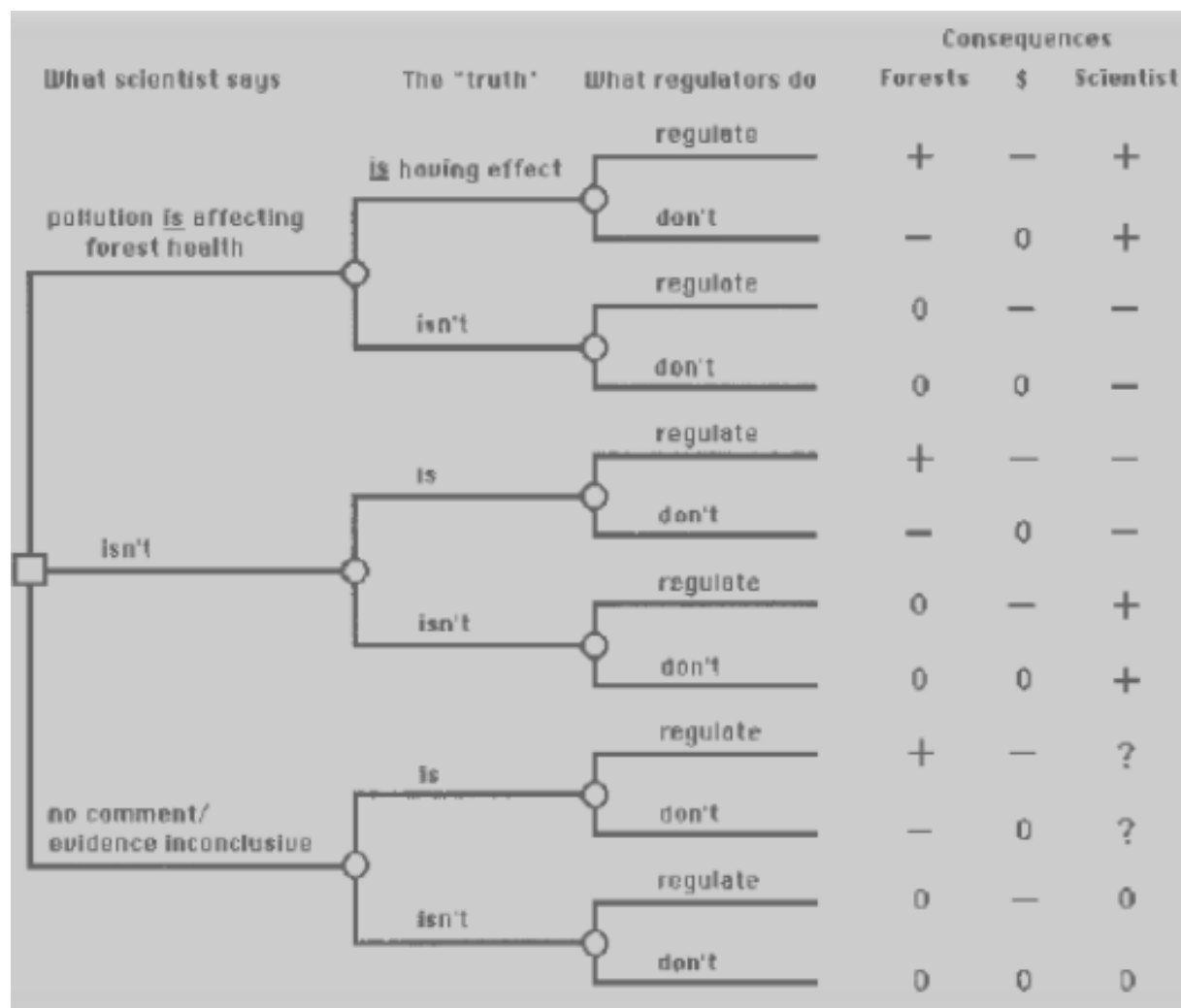

Figure 2.7: Decision tree for analysis of regulation on air quality intended to improve forest-health.

- The squares represent points in the tree over which you have control as a decision maker, i.e., they represent the decisions you can make. In this case our decision is what to tell the person who asked for our opinion.

- The circles represent points in the tree over which you have no control.

- Along each branch of the tree, all possibilities are considered.

The consequences of following each branch of the tree can be evaluated for several different variables. Notice that the payoffs to the scientist and the forest are not the same. More importantly, they payoffs are measured in different units. They're not easy to compare ${ }^{[2]}$.

\section{Conclusions}

This paper is an attempt to highlight the information, methods of decision making under risk and uncertainty. From the study the important points observed are as follows.

1)The words "risk" and "uncertainty" emphasize that the decision-making must be made on the basis of incomplete information and the outcome is unknown to decisionmaker.

2)A risk management framework needs to be formulated to minimize or eliminate adverse consequences that may arise.

3) In the most of countries decision making scenarios i.e. different possibilities are adopted for a project development.

4)To avoid risky situation decisions should be made after the proper investigation.

5)By using decision tree worst, best and expected values can be determined for different scenarios.

\section{References}

[1] Piyatrapoomi.N., Kumar.A, Setunge.S, "Framework for Investment Decision-Making Risk and Uncertainty for infrastructure asset management," (Professors of Civil Engineering, RMIT University, Melbourne, Australia).

[2] Holsinger E. Kent, "Decision Making under Uncertainty: Statistical Decision Theory".

[3] Schultz T. Martin, Mitchell N. Kenneth, Harper K. Brian and ssBridges S. Todd, "Decision Making Under Uncertainty" U.S. Army Engineer Research and Development Center, November 2010.

[4] Weber U. Elke and Johnson J. Eric "Decision under Uncertainty: Psychological, Economic, and Neuro economic Explanations of Risk Preference,"

[5] Riabacke Ari, "Managerial Decision Making Under Risk and Uncertainty," IAENG International Journal of Computer Science, 32:4, IJCS_32_4_12

[6] Piyatrapoomi Noppadol and Kumar Arun, Investment sInfrastructure Asset Management," QUTDiSgitalRepository:http://eprints.qut.edu.au/26881,

[7] Guerron A. Pablo Quintana "Risk and Uncertainty" 2012 Business Review.

[8] David E. Bell E.David \& Schleifer Arthur,"Decision Making under Uncertainty" Jr. India Edition 1995

[9] N.D.Vohra, "Quantitative Techniques in Management" McGrawHill Education, New Delhi.

\section{Author Profile}

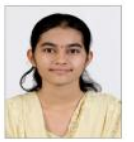

Manjushree Kurhade, B.E. Civil Engineering (2013); M.E.Construction Engineering \& Management; Decision making (Decision Making under Risk \& Uncertainty) 